\title{
Adli Psikoloji’nin Tarihine Kısa Bir Bakıș
}

\section{ÖZET}

Nesrin DUMAN ${ }^{1}$

Adli psikoloji dünyada hızla büyüyen ve gelişen psikoloji uzmanlık alanlarından biridir. Psikoloji, hukuk içerisinde çok eski zamanlardan beri yer almaktadır. Ancak psikoloji bilimi, Leipzig Üniversitesi'nde ilk psikoloji laboratuvarının kurulmasıyla resmî akademik bir disiplin olabilmiştir. Bu labaratuvarda yetişen donanımlı psikologlar Avrupa'ya ve sonrasında Amerika'ya dağılmışlardır. Peşi sıra açılan yeni psikoloji laboratuvarlarında da pek çok araştırma yürütülmüştür. Elde edilen araştırma bulgularından adli sistemin çeşitli safhalarında faydalanılmıştır. Akıl hastalığı-ceza ehliyeti ilişkisi ile başlayan hukuk-psikoloji ilişkisi, zaman içerisinde tanık ifadelerinin güvenilirliğinin incelenmesi ile derinlik kazanmıştır. Psikologlar zaman içerisinde mahkemelerde daha fazla görev alıp, çeşitli konularda uzman görüşlerini bildirmişlerdir. Savaş dönemi sonrasında psikologlar mahkemelerde çok sık yer almışlardır. Adli psikolojinin ivme kazanması 1970'lerden sonra olmuş, en nihayetinde 2010 yılında adli psikoloji Amerikan Psikoloji Birliği (APA) tarafından resmi uzmanlık branşı olarak kabul edilmiştir. Bu çalışmada adli psikiyatrinin ve dolayısıyla adli psikolojinin temelini oluşturan "McNaughten Kuralları"nın ortaya çıkış süreci, yargı sürecine katkı sağlayan önemli isimler ve psikolojik araştırmaları, psikologların mahkemelerde görev alışları, adli psikolojinin resmi uzmanlık branşı olarak tanınması ve son dönem gelişim süreci ele alınacaktır.

Anahtar Kelimeler: Adli, psikoloji, tarihçe.

\begin{abstract}
A Brief Overview of the History of Forensic Psychology

Forensic psychology is one of the rapidly growing and developing psychology specialties in the world. Psychology has been in law since ancient times. However, the science of psychology became an official academic discipline with the establishment of the first psychology laboratory at the University of Leipzig. Welleducated psychologists here are spread throughout Europe and then to America. Many researches have also been carried out in new psychology laboratories that are opened one after another. The research findings obtained have been used in various phases of the forensic system. The relationship between law and psychology, which started with the mental illness-criminal capacity relationship, has gained depth by examining the reliability of witness statements over time. Psychologists have taken more positions in courts over time and have expressed their expert opinions on various topics. After the world war period, psychologists were very often present in courts. The acceleration of forensic psychology came after the 1970s, and finaly in 2010, forensic psychology was recognized as a specialization branch by the American Psychological Association (APA). In this study, the emergence process of "McNaughten Rules", which forms the basis of forensic psychiatry and therefore forensic psychology, important names and psychological researches contributing to the judicial process, psychologists' acceptance in courts, recognition of forensic psychology as an official speciality and the recent development process.
\end{abstract}

Keywords: Forensic, psychology, history.

\section{GíRIŞ}

Adli psikoloji, kısmen suçlu profillemesinin cazip miti, kısmen de suç ve suçlulara olan yoğun ilgi nedeniyle, dünyada hızla büyüyen psikoloji uzmanlık alanlarından biridir. Adli psikoloji, psikolojinin bilgi ve deneyimlerinden yararlanarak adli sistemin çeşitli safhalarında, giderek genişleyen konularda

${ }^{1}$ Dr.Öğretim Üyesi, İstanbul Ayvansaray Üniversitesi, Psikoloji Bölümü, nesrinduman@ayvansaray.edu.tr 
yer almaktadır. Kriminoloji, adli psikiyatri ve hukuk arasında yer alan adli psikoloji, insan coğrafyası (human geography), klinik, gelişim ve sosyal psikoloji, sosyo-hukuki çalışmalar ve psikometri gibi çeşitli disiplinlerden de yararlanmaktadır (Carter, 2010, s.3).

Adli psikolojinin tarihine bakıldığında, psikolojinin adli süreçler içerisinde yer almasının çok erken tarihlerde başlamış olduğu anlaşılmaktadır. Ancak "psikoloji”"nin pozitif bir bilim olarak kabulünün 1879 yılında olması (ilk psikoloji laboratuvarının açılışıyla) nedeniyle; bu tarihten önceki gelişmeler adli psikiyatri ile iç içe geçmektedir. Burada psikiyatri ile psikoloji arasındaki temel farkın belirtilmesi yararlı olacaktır. Psikiyatri akıl hastalığına odaklanan tıbbi bir uzmanlık iken; psikologların tıbbi nitelikleri bulunmamaktadır. Ancak akıl hastalıkları olan insanlarla çalışmayı isteyen psikologlar, bu alanda yüksek derecelerini alıp uzmanlaşabilmektedir. Bu şekilde ihtisaslaşan psikologlar "klinik psikolog" olarak adlandırılmaktadır (Carter, 2010, s.4). Bu haliyle klinik psikoloji, adli psikolojiye en yakın alanlardan biridir. Dolayısıyla akıl hastalıkları sadece adli psikiyatrinin değil adli psikolojinin tarihinde de önemli bir yerde durmaktadır.

$\mathrm{Bu}$ çalışmada adli psikolojinin tarihine kısa bir seyahat gerçekleştirilecektir. Adli psikiyatrinin ve dolayısıyla adli psikolojinin temelini oluşturan "McNaughten Kuralları"nın ortaya çıkış süreci, hukuk sistemine katkı sağlayan önemli isimler ve psikolojik araştırmaları, psikologların mahkemelerde görev alışları, adli psikolojinin resmi uzmanlık branşı olarak tanınması ve son dönem gelişim süreci incelenecektir.

\section{Mc Naughten Kuralları}

20 Ocak 1843'te İskoçya-Glasgow'da yaşayan, Daniel Mc Naughten isimli 29 yaşındaki bir ahşap oymacısı başbakanı (İngiltere) öldürmeye kalkışır. Başbakan Sir Robert Peel, o dönem İngiltere'sinde kiliseye-krala bağlı muhafazalar parti olan Tory partisinin de başkanıdır. Silahlı saldırı sırasında McNaughten, başbakan yerine yanlışlıkla onun özel sekreteri Edward Drummond'u vurur. Drummond, hafif yaralanır, ancak olaydan birkaç gün sonra tedavi gördüğü hastanede komplikasyon nedeniyle hayatını kaybeder (Carter, 2010, s.6).

McNaughten, öldürme motivasyonunu belirttiği tek halk açılamasında şunları söyler: "Kendi şehrimdeki Tory'ler (The Tories) beni bunu yapmaya zorladl. Nereye gidersem gideyim beni takip ediyorlar, zulmediyorlar ve zihnimin huzurunu tamamen yok ettiler. Beni Fransa'ya, İskoçya'ya ve tüm Ingiltere'ye kadar takip ettiler. Aslında beni nereye gidersem takip ediyorlar. Uyuyamıyorum ya da onlar yüzünden dinlenemiyorum. Asla eskiden olduğum kişi olmayacă̆ım. Önceden iyi bir să̆lı̆̆ım ve gücüm vardl, ama şimdi yok (akt. Brigham, 1999; Moran, 1981, s.10)”

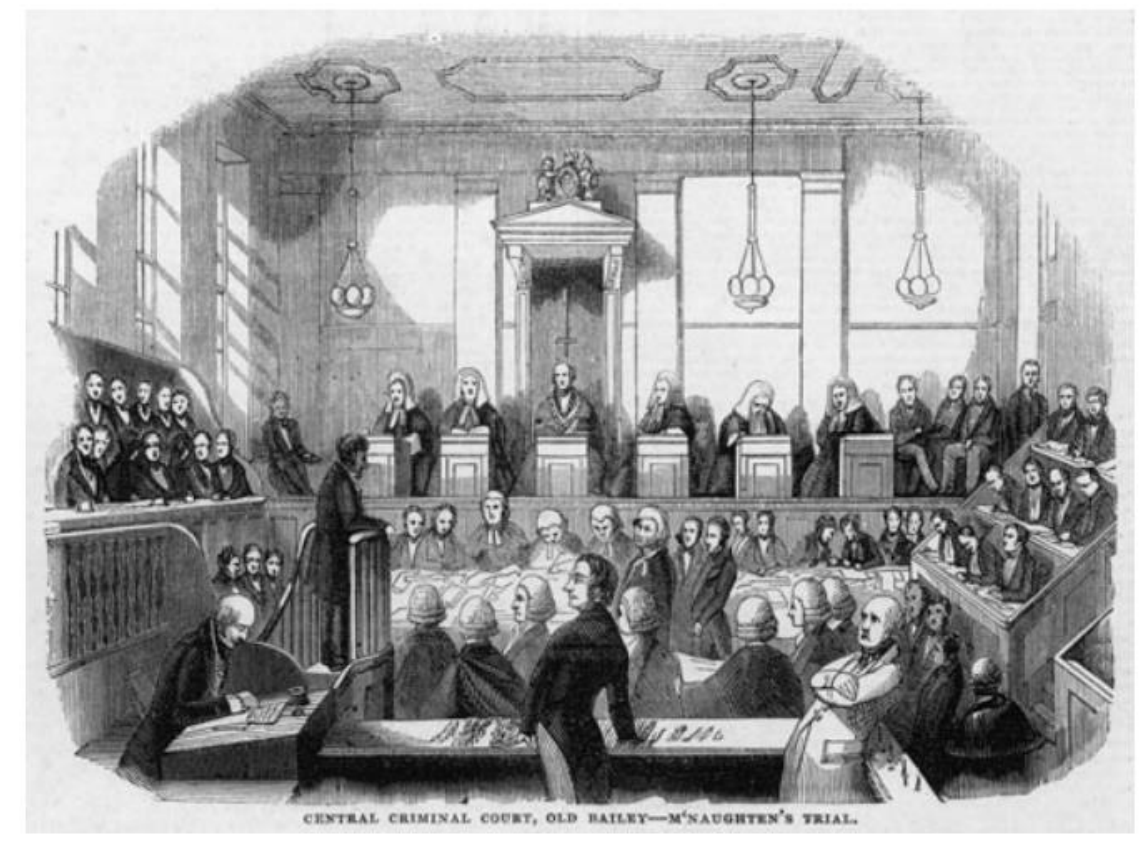

Resim 1. McNaughten'1n yargılandığı mahkeme (Carter, 2010, s.7).

$\mathrm{Bu}$ sözlerinden anlaşılacağı üzere McNaughten perseküsyon (kötülük görme) hezeyanlarından muzdaripti ve Tory partisinin zarar verici eylemleri nedeniyle yaşamının tehlike altında olduğuna 
inanmaktaydı (Biswas s.365). McNaughten'ın yargılaması sırasında dokuz tıbbi bilirkişi “akıl hastası (insane)" ya da "kısmi akıl hastası (partial insane)" görüşlerini bildirerek Mc Naughten'ın lehine ifade vermiştir (Brigham, 1999). Jüri de hızlı bir şekilde "akıl hastalığı nedeniyle suçlu değil” kararını açıklamıştır. McNaughten bu karar neticesinde yirmi bir yıl boyunca akıl hastanesinde yatılı tedavi altına alınmıştır. Bu vaka neticesinde İngiliz Lordlar Kamarası (House of Lords) tarafından "McNaughten Kuralları (Mc Naughten Rules)" oluşturulmuştur. Mc Naughten kuralları şu kriterlerden oluşur: Akıl hastalığ temelinde bir savunma oluşturmak için, "kişinin eylemi gerçekleştirdiği sırada böyle bir muhakeme arazı altında olması, akıl hastalı̆̆ından muzdarip olması, bu nedenle yaptığl eylemin doğasını ve niteliğini bilmemesi, ĕger biliyorsa da yaptığının yanlış olduğunu bilmemesi" gerekir.

Mc Naughten kuralları İngiltere'de akıl hastalığı durumlarında yasal sorumluluğu düzenleyen yasanın temeli haline gelmiştir. Bu kurallar çok kısa bir süre içerisinde Birleşik Devletler tarafından da eyaletlerin neredeyse yarısı ("Insanity defense", 2020; Brigham, 1999)- benimsenmiştir. McNaughten kuralları, Amerikan mahkemelerinde ve yasama organlarında 20. yüzyılın ortalarına kadar neredeyse hiçbir değişiklik yapılmadan kullanılmıştır ("From Daniel M'Naughten”, 2020). 1998 yılında yirmi beş eyaletin ve Columbia Bölgesi (District of Columbia)'nin akıl hastalığını değerlendirmek için M'Naughten kurallarının versiyonlarını kullanmakta olduğu bilinmektedir ("From Daniel M'Naughten", 2020).

Ülkemizde ise 2004 yılında Resmi Gazete'de yayımlanarak yürürlüğe giren 5237 sayılı Türk Ceza Kanunu'nun 32. maddesinde akıl hastalarının ceza sorumluluğuna ilişkin düzenleme yapılmıştır. Günümüzde akıl hastalarının isnat (kusur) yeteneklerinin değerlendirilmesi bu kanun maddesine göre yapılmaktadır.

\section{Psikologların mahkemelerde görev alması}

Psikolojinin daha doğrusu psikiyatrinin adli süreçler içerisinde yer alması öncelikle akıl hastalığı-ceza ehliyeti ilişkisi ile olmuştur. 1879 yılında resmî akademik bir disiplin olarak psikoloji biliminin kurulması ile insan doğası ve insan davranışları psikolojinin kendi yöntemleriyle açıklanmaya çalışılmıştır. Psikoloji, insan naturası ve davranışları için olgulara dayalı açıklamalar bulmaya yönelmiş, test ve teknikler geliştirmiş, insanı sistematik olarak incelemiş ve deneysel araştırmaların sonuçlarından yararlanmıştır.

Yirminci yüzyılın ilk yıllarında, genç psikoloji disiplinini yasal sistemin içine dâhil etmek için birkaç önemli girişim yapılmıştır. Çok farklı bakış açılarına sahip iki öncü isim Sigmund Freud ve Hugo Münsterberg psikolojinin yasalar için önemli uygulamaları olduğunu savunmuştur (Brigham, 1999). 1906'da Avusturyalı hâkimlerle yapılan bir konuşmada Freud (1906/1959) psikolojinin işleriyle çok ilişkili olduğunu iddia etmiştir. Freud, psikanalizden uyarlanan prosedürlerin, özellikle de kelime çağrıştırma tekniği (word association technique)nin yeni bir soruşturma yöntemi oluşturabileceğini öne sürmüştür. Freud'un bu önerisi, bir pırıltı olarak tarih sayfalarında beklemeyi sürdürmektedir. Münsterberg de bir makalesinde avukatların psikoloji bilimine dikkat vermelerini önemle vurgulamıştır (akt. Brigham, 1999; Münsterberg, 1908). Münsterberg aynı y1l ilk adli psikoloji kitabını (On the Witness Stand: Essays on Psychology and Crime) yayınlamıştır. Ancak "Psikoloji ve Hukuk"un önemli bir araştırma alanı olduğuna dair yaygın mesleki kabul 1960'larda ve 1970'lerde ivme kazanmıştır (Brigham, 1999). Psikoloji biliminin kurulmasından itibaren yapılan pek çok araştırma bu kabulün sağlanması yolundaki taşları yavaş yavaş dizmiştir.

\section{Adli psikolojiye katkı sağlayan bazı araştırmacılar}

Leipzig Üniversitesi'nde ilk psikoloji laboratuvarının kurulmasıyla burada yetişen donanımlı psikologlar Avrupa'ya ve sonrasında Amerika'ya yayılmışlardır. Leipzig'de kurulan laboratuvardan sonra Göttingen, Berlin, Würzburg'da yeni laboratuvarlar açılmış (Saugstad, 2018, s.50), buralarda da önemli araştırmalar yürütülmüştür. Amerika'da 1883 yılında John Hopkins Üniversitesi'nde bir laboratuvar kurulmuş (Saugstad, 2018, s.236) ve öğrenciler yetiştirilmiştir. Tüm bu çalışmacılar 
sürdürdükleri araştırmaların sonuçları ile yargıya katkı sağlamaya başlamışlardır. Bu isimler arasında Cattell, Schrenck-Notzing, Stern ve Marbe oldukça önemlidir.

\section{James McKeen Cattell}

James McKeen Cattell, Leipzig Üniversitesi'nde yetişmiş (Wundt'un öğrencisidir) bir psikologdur. Adli psikoloji alanındaki ilk araştırma Cattell tarafından 1893 yılında Columbia Üniversitesi'nde yapılmıştır. Cattell, 56 üniversite son sınıf öğrencisine bir dizi soru sorarak çok çeşitli bilgilerin hatırlanma düzeylerini incelemeye almıştır. Cattell, öğrencilere "Sonbaharda meşe ağacı mı kestane ă̆acı mı daha erken yaprak döker?, Bir hafta önce bugün hava nasıldı?, Atlar başlarıyla mı kuyruklarıyla mı rüzgara karşı durur?, Bir elmanın tohumları hangi yöne işaret eder?" sorularını yöneltmiştir (Loftus, 1996, s.27-8). Cattell ayrıca öğrencilerden kendinden eminlik düzeylerini de numaralandırmalarını istemiştir. Araştırmasının sonucu doğru yanıt verme ile kendinden eminlik düzeyinin aynı olmadığını göstermiştir. Bazı öğrenciler yanıtların doğru olup olmadığından bağımsız olarak kendilerinden son derece eminken; bazı öğrenciler doğru cevabı verdikleri halde kendilerinden emin değillerdi. Cattell, daha sonra öğrencilere ağırlık, mesafe ve zamanı tahmin etmeye yönelik bir takım sorular "Sınıfta kullanılan kitabın ă̆ırlı̆̆ nedir?, Üniversitedeki iki bina arasındaki mesafe nedir?, Öğrenciler binanın ana giriş kapısından sınıf kapısına kaç dakikada yürürler?" daha sormuştur (Loftus, 1996, s.28). Cattell, araştırma bulgularının mahkemede kendisine yararlı bir uygulama alanı (zaman aşımı, doğruluk eksikliği, kişisel ilginin etkisi gibi) bulacağını hissetmiştir. Alfred Binet, Cattell'in araştırma sonuçlarını Fransa'da tekrar edip geliştirmiştir. (Akdaş ve Oral, 2006). Binet (1900) yönlendirici soruların yanıtları etkilediğini ilk ifade eden kişidir (akt. Wells, Memon ve Penrod, 2006). Joseph Jastrow ise Wisconsin Üniversitesi'nde çalışmayı tekrar etmiş ve Cattell ile aynı sonuçlara ulaşmıştır (Bolton, 1896).

\section{Albert Von Schrenck-Notzing}

Albert Von Schrenck-Notzing, Münih Üniversitesi'nde yetişmiş fizikçi, psikiyatrist, psişik araştırmacı ve seksologdur (Tymn, 2011). Aynı zamanda yine bir Leipzig öğrencisidir (Gudjonsson ve Haward, 1999, s.10). Paranormal olaylar, medyumluk, hipnoz, telepati, telekinezi gibi konularda çalışmalar yapmıştır (Sommer, 2012). Schrenck-Notzing, 1896 yılında Münih'de bir mahkemede görülmekte olan bir cinayet davasında modern anlamda ilk adli psikolog olarak görev almıştır (Gudjonsson ve Haward, 1999, s.10). Bu davada bir adam üç kadını öldürmekle suçlanmaktadır (Farah, 2020). Duruşmaya kadar geçen aylarda olayla ilgili medyada muazzam miktarda sansasyonel haberler yapılmıştır (Brown, Shell ve Cole, 2015, s.48). Schrenck-Notzing, bu yayınların sonucu olarak tanıkların gerçek hatıraları ile gazete ve dergilerde gördükleri detayları birbirinden ayırt edemeyebileceğini ileri sürmüştür. "Retroaktif hafıza tahrifi (retroactive memory falsification)" olarak ifade ettiği, insanların gazetede okudukları ve medyada gördükleri ile gerçek hayatta gördüklerini birbirine karıştırdığına dair araştırma bulgusunu mahkemede sunmuştur. Bu araştırma sonuçları tanık ifadelerinin güvenilirliği hususunda mahkemenin karar vermesinde yardımcı olmuştur. Dava sonucunda sanık suçlu bulunmuştur, ama uzman görüşü diğer psikologların ilgisini çekmiştir (Gudjonsson ve Haward, 1999, s.10).

\section{William Stern}

William Stern, Berlin Üniversitesi'nde yetişmiş bir psikologdur. 1901 yılında öğrencilerin hatırlamalarının doğruluk düzeyini araştırmaya başlamıştır (Stern, 1939). Adli bilimlere katkı sağlayan "gerçek hayata en yakın" deneysel araştırmasını ise Alman kriminolog Franz von Liszt ile Berlin Üniversitesi'nde ortaklaşa yürütmüşlerdir. Araştırmacılar, hukuk dersinde iki öğrenci arasında bilimsel bir münazara üzerine sahte bir tartışma sahneleyen bir "gerçeklik deneyi" yapmışlardır. Deneyde öğrencilerin "sahte" tartışması bir süre hızlanarak devam etmiş, nihayetinde öğrencilerden biri diğerine silah çekmiş, bu noktada Stern araya girmiştir (Stern, 1939). Stern, anlaşmazlığın yönleri hakkında sınıftan yazılı ve sözlü raporlar istemiştir. Öğrenciler nasıl rapor hazırlayacaklarını bilmelerine rağmen, hiçbir ögrenci hatasız bir rapor sunamamıştır. Çünkü kavganın görünen ciddiyetine olan ilgiye güçlü bir duygusal şok eşlik etmiştir. $\mathrm{Bu}$ araştırma sonucunda duygusal reaksiyonların kesin gözlemi ve güvenilir hatırlamayı engellediği ortaya koyulmuştur (Stern, 1939). 
Stern'in araştırması pek çok araştırmacıya ilham vermiştir. Örneğin, Berkowitz ve LePage (1967) Wisconsin Üniversitesi'nde deneysel bir araştırma yürütmüşlerdir. Araştırmalarında bir denek, işbirlikçi kişi tarafından kızdırılmıştır. Ardından denek bir masaya oturtulmuştur. Birinci düzenekte masanın üstünde silah vardır. İkinci düzenekte ise masada spor malzemeleri (badminton raketi ve topu) vardır. Bulundukları ortamda deneğe "seni kızdıran kişiye elektrik şoku vermek istesen hangi düzeyde şok verirsin? sorusu yöneltilmiştir. Araştırma sonuçlarında silah olan masaya oturan deneklerin şok düzeyini daha yüksek söyledikleri bulunmuştur. Berkowitz ve LePage (1967) ortamda silahın bulunmasının agresif davranışları artırdığını ortaya koyarak; "silah etkisi (weapon effect)" terimini literatüre kazandırmışlardır.

Loftus, Loftus ve Messo (1987) ise Washington Üniversitesi'nde psikoloji bölümü öğrencileriyle silah odağı etkisi üzerine deneysel bir çalışma yürütmüşlerdir. "Silah odağı (weapon focus)"; bir suç tanığının dikkatini bir silaha yoğunlaştırması ve bunun sonucunda da suçun diğer ayrıntılarını hatırlama yeteneğindeki azalma anlamına gelmektedir. Deney grubuna bir restaurantın önünde sırada ilerleyen bir grup insanın olduğu 35 mm'lik 18 adet slayt gösterilmiştir. Slaytların sonunda bir adam kasiyere silah çekmiştir. Kontrol grubunda ise aynı adam kasiyere çek uzatmıştır. Araştırmalarının sonucunda silahın olduğu durumda insanların silaha daha uzun süre baktıkları, bu nedenle kişiyi tanımlamada zorlandıkları ortaya koyulmuştur. Araştırmacılar, bu bulgularını silahın varlığında insanların daha uyarılmış vaziyette oldukları, bu durumun da dikkatte daralmaya neden olduğu şeklinde açıklamışlardır. Loftus ve arkadaşları daha sonra bu araştırmalarını 80 öğrenci ile tekrarlamış, benzer sonuçlara ulaşmıştır.

\section{Karl Marbe}

Bir başka Leipzig öğrencisi (Wundt'un öğrencisidir) Alman psikolog Karl Marbe, Wurzburg'da bir mahkemede görülmekte olan cinsel saldırı davasında ilk yasal uzman görüşünü bildirmiştir (Marbe, 1936, s.184). Davada birkaç ergen kız, öğretmenlerini cinsel sömürü nedeniyle suçlamaktadır. Marbe, çocukların ifadelerinin güvenilirliği konusunda araştırma sonuçlarını mahkemeye sunarak, çocukların beyanlarına güvenilmeyeceği yönünde görüş bildirmiştir. Yine 1911'de, Belçika'da bir cinayet davasında birkaç psikoloğun mahkemede görüş sundukları tarih kayıtlarına geçmiştir. Söz konusu davada bir adam dokuz yaşındaki bir kıza tecavüz etmek ve öldürmekle suçlanmaktadır. Çocuğun oyun arkadaşlarından ikisi katili görmüştür. Ama çocukların tutarsız ve çelişkili beyanlar vermeleri yargılamayı zorlaştırmıştır. Bunun üzerine psikologlardan biri olan Julian Varendonck, aynı yaş grubundaki çocuklarla yaptığı deneysel bir araștırmasının sonuçlarını mahkemeye sunmuştur. Araştırma sonuçları çocukların önemli olayları hatırlamalarında yanlışlıkları olduğunu ortaya koymaktaydı. Bu görüş neticesinde davada jüri sanığın suçsuz olduğu kararına varmıştır ("History of Courtroom Testimony", 2020).

1912 yılında bu kez Marbe'dan, Mullheim yakınlarında gerçekleşen bir tren kazası için açılan sivil bir davada uzman görüşü istenmiştir. Marbe, alkolün mühendisin zihin durumuna etkisi ile itfaiyecinin ve frene basan nöbetçinin reaksiyon zamanına etkisi üzerine görüşlerini sunmuştur. Reaksiyon süresi deneylerine dayanarak Marbe, bu felaketi önlemek için trenin zamanında durdurulamayacağını doğrulamıştır ("History of Courtroom Testimony", 2020).

Adli psikolojiye katkı sağlayan çalışmalar elbette bu kadarla sınırlı değildir. 1921 yılında Amerika'da Coca-Cola şirketi ile Chero-Cola şirketi arasında yaşanan logo anlaşmazlığ ticari marka ihlali davasını doğurmuştur. Bu davada psikologlardan "Benzer logolar halkın zihnini karıştırır mı? Tüketicinin aldatılmasına yol açar mı?" soruları için görüş istenmiştir. Aynı yıl Amerika'da ilk kez bir psikolog bilirkişi ünvanıyla mahkemede görev almıştır (Kocsis, 2009, s.45). Batı Virginia mahkemesinde görülmekte olan çocuk cinsel istismarı davasında Ergen Araştırmaları Bürosu (State Bureau of Juvenile Research) şef psikoloğu çocuk suçluluğu konusunda uzman olarak mahkemeye kabul edilmiştir ("History of Expert Testimony", 2020). Davadaki mağdur çocukta (12 yaş) entelektüel bozukluk vardır ve ifadelerinin güvenilirliği tartışma konusudur. Psikolog bilirkişi, psikolojik test verilerine dayanarak görüş bildirmiştir. Mahkeme, psikoloğun "bir tecavüz girişiminin kurbanı olduğu iddia edilen 12 yaşındaki klz çocuğunun "moron" olduğu ve beyanlarına inanılamayacağı"na dair görüşünü reddetmiştir. 
Araştırma amacıyla gerçek suçlulara, jüriye (Anglo Saxon hukuku (Common Law) ülkelerindeki bir uygulamadır), tanıklara veya polis memurlarına erişim her zaman yasal ve uygulamadaki kısıtlamalarla doludur. Bazı durumlarda, planlanması ve kaçınılması gereken gerçek tehlikeler de söz konusudur. Bu nedenle, adli psikoloji ile özellikle görgü tanıklığı ifadesi ile ilgili pek çok araştırma, genellikle gerçekçi olmayan senaryolardan oluşan, daha sonra öğrencilerin neyi hatırladıklarını belirtmelerinin istendiği videoların gösterildiği oldukça yapay ortamlarda gerçekleştirilmiştir. Bunun laboratuvar dışında uygulanabilirliği oldukça sınırlıdır, çünkü bu araştırmalar simülasyonlara dayandırılmıştır, denekler gerçek baskı altında olmayan bir popülasyondan sınırlı bir alt kümesinden oluşmuştur (Carter, 2010, s.14).

$\mathrm{Bu}$ tarihlerden sonra yaklaşık 1950'lere kadar psikologların mahkemelerde görev almalarına pek rastlanılmadığı görülmektedir (Akdaş ve Oral, 2006). Bu dönemde psikologların orduda ölçmedeğerlendirme ve askerlere klinik hizmet verme gibi görevlerde bulundukları bilinmektedir. Savaş sonrasında ise askerlerde travma sonrası stres bozukluğu (TSSB) etkilerin tartışılması ve travmatik etkiler ile ceza-i ehliyet ilişkisinin incelendiği araştırmalar ile psikologların mahkemedeki yerleri gittikçe güçlenmeye başlamıştır (Akdaş ve Oral, 2006). Adli psikolojinin mesleki kabulü 1968 yılındaki organizasyonel toplantının akabinde (Grisso, 1991), 1969 yılında Amerika Hukuk ve Psikoloji Birliği’nin kurulmasıyla hız kazanmıştır. Daha sonraki süreçte göze çarpan bazı önemli gelişmeler Tablo 1'de sunulmuştur.

Tablo 1. Savaş dönemi sonrasında Adli Psikoloji alanındaki önemli gelişmeler

\begin{tabular}{ll}
\hline Yıl & Önemli gelişme \\
\hline 1969 & Amerika Hukuk ve Psikoloji Birliği (American Psychology-Law Society) kurulması \\
1974 & Nebraska Üniversitesi’nde Hukuk-Psikoloji ortak yüksek lisans programı açılması \\
1976 & Amerika Adli Psikoloji Kurulu (American Board of Forensic Psychology) kurulması \\
1981 & $\begin{array}{l}\text { APA, Bölüm/Daire 41- Amerika Psikoloji-Hukuk Birliği (Division 41-American Psychology- } \\
\end{array}$ \\
& Law Society) kurulması
\end{tabular}

1982 Türkiye, 41 sayılı KHK ile İ.Ü. Adli Tıp Enstitüsü kurulması

1983 Türkiye, 41 sayılı KHK değ. ile A.Ü. Adli Bilimler Enstitüsü kurulması

1991 APA, adli psikologlar için etik kuralların belirlenmesi (bildirge)

(Specialty Guidelines for Forensic Psychologists)

1998 Amerika'da 5 üniversitede hukuk-psikoloji ortak doktora programları açılması

2001 APA, adli psikolojinin resmi uzmanlık branşı olarak kabul edilmesi

2008 APA, adli psikolojinin yeniden sertifikalandırılması

2013 APA, adli psikoloji için etik kuralların revize edilmesi, isim değişikliği

(Specialty Guidelines for Forensic Psychology)

\section{SONUÇ}

Adli psikolojinin ivme kazanması 1970'lerden bu yana özellikle belirgin olmasına rağmen, tarihi Cattell'in çok basit bir psikolojik deney gerçekleştirdiği 19. yüzyılın sonuna kadar izlenebilmektedir (Bartol ve Bartol, 2019, s.50). Bir ceza davasının başarılı bir şekilde kovuşturulabilmesi için mağdur ve tanıkların ifadesi çok önemlidir (akt. Duman, 2018; Holder, 2013:1158). Bu nedenledir ki o günden bugüne, hem hafıza hem de görgü tanığı araştırmaları, birçok adli psikoloğun ilgisini çekmeye devam etmektedir. Psikologlar adli sistem için büyük değer taşıyan bilgiler üreten başka konuları da incelemişlerdir. İnsan bilişi, çocuk gelişimi, anormal davranış, yalan/aldatmanın tespiti ve stres üzerine yapılan araştırmalar bu konulara sadece birkaç örnektir. 20. yüzyılda, bu tür psikolojik bilgiler, önce sivil mahkemelerde ve daha sonra ceza mahkemelerinde, bilirkişi ifadesi şeklinde yasal işlemlere aşamalı olarak sokulmuştur. 
Psikologlar 1960-70'li yıllarda artan bir biçimde mahkemelerde görev almışlardır. Adli psikoloji sertifikası Amerikan Adli Psikoloji Kurulu (American Board of Forensic Psychology) tarafindan 1978 'de verilmeye başlamıştır (akt. Bartol ve Bartol, 2019, s.50; Otto ve Heilbrun, 2002). Kısa bir süre sonra, Amerikan Psikoloji Derneği (APA), Bölüm/Daire 41, Amerikan Psikoloji-Hukuk Birliği kurulmuş ve bu birim APA'y1 1991'de Adli Psikoloji yönergelerini (Specialty Guidelines for Forensic Psychologists) benimsemeye yönlendirmiştir. Yönerge 2013 'te revize edilmiştir (APA, 2013).

Adli psikoloji, APA tarafından 2001 yılında uzmanlık alanı olarak kabul edilmiş ve 2008 yılında yeniden sertifikalandırılmıştır. Adli psikolojinin olgunlaştığı ancak 2010 yılında dile getirilmeye başlanmıştır. Adli psikolojinin büyümesi, adli psikoloji araştırma ve uygulamalarına ayrılmış mesleki kuruluşların gelişimine, konuya odaklanan kitap ve süreli yayınlarda önemli artışlara, lisans ve lisansüstü eğitim programlarının geliştirilmesine, alanda çalışan uzmanların standartlarının belirlenmesine yansımaktadır. Tüm bu gelişmelerin ülkemizde de gerçekleşmesi temenni edilmektedir.

\section{KAYNAKLAR}

Akdaş, A., \& Oral, G. (2006). Akademik bir disiplin ve uygulama alanı olarak adli psikoloji. Türk Psikoloji Yazllarl, 9(17),71-90.

American Psychology Association. (2013). Specialty guidelines for forensic psychology. American Psychologist, 68(1), 7-19.

Bartol, C. R., \& Bartol, A. M. (2019). Introduction to forensic psychology: Research and application $\left(5^{\text {th }}\right.$ Edition). Los Angeles London New Delhi Singapore Washington DC Melbourne: Sage Publications, Inc.

Berkowitz, L., \& LePage, A. (1967). Weapons as aggression-eliciting stimuli. Journal of Personality and Social Psychology, 7, 202-7.

Binet, A. (1900). La suggestibilite' [On suggestibility]. Paris: Schleicher.

Biswas, G. Review of forensic medicine and toxicology: Including clinical \& pathological aspects. $2^{\text {nd }}$ edition. New Delhi Panama City London:Jaypee Brothers Medical Publishers (P) Ltd.

Bolton, F. E. (1896). The accuracy of recollection and observation. Psychological Review, 3(3), 28695. https://doi.org/10.1037/h0073741s

Brigham, J. C. (1999). What is forensic psychology, anyway? Law and Human Behavior, 23(3), $273-$ 98. https://doi.org/10.1023/A:1022304414537

Brown, J., Shell, Y., \& Cole, T. (2015). Forensic psychology: Theory, research, policy and practice. Los Angeles London New Delhi Singapore Washington DC Melbourne: Sage Publications, Inc.

Carter, D. (2010). Forensic psychology: A very short introduction. New York: Oxford University Press.

Duman, N. (2018). Koruyucu ve destekleyici önlem olarak çocukların mağdur olarak bulunduğu davalarda hayvanların kullanımı. R\&S - Research Studies Anatolia Journal, 1(2), 368-75.

Freud, S. (1906/1959). Psycho-analysis and the establishment of the facts in legal proceedings. In J. Strachey (Ed.), The standard edition of the complete psychological works of Sigmund Freud, Volume 9 (pp. 103-114). London: Hogarth.

From Daniel M'Naughten to John Hinckley: A brief history of the insanity defense. (2020, 31 Mayı). Erişim adresi: https://www.pbs.org/wgbh/pages/frontline/shows/crime/trial/history.html 
Grisso, T. A. (1991). Developmental history of the American Psychology-Law Society. Law Hum Behav, 15, 213-31. https://doi.org/10.1007/BF01061710

Gudjonsson G. H., \& Haward, L. R. C. (1999). Forensic psychology: A guide to practice (2 ${ }^{\text {nd }}$ ed.). NY: Routledge Pub.

History of Courtroom Testimony. (2020). Erişim adresi: http://criminaljustice.iresearchnet.com/forensic-psychology/history-of-forensic-psychology/courtroom-testimony/

Holder, C. (2013). All dogs go to court: the impact of court facility dogs as comfort for child witnesses on a defendant's right to a fair trial. Houston Law Review. Symposium 2013, 50(4), 1155-87.

Insanity defense. (2020, 31 Mayıs). Erişim adresi: https://www.law.cornell.edu/wex/insanity_defense

Kocsis, R. N. (2009). Applied criminal psychology: A Guide to forensic behavioral sciences. Springfield, Illinois USA:Charles C ThomasPublisher Ltd.

Loftus, E. F. (1996). Eyewitness testimony. Cambridge, Massachusetts: Harward University Press.

Loftus, E. F., Loftus, G. R., \& Messo, J. (1987) 'Some facts about “weapon focus"'. Law and Human Behaviour, 11: 55-62

Marbe, K. (1936). Work in commercial high schools and practical attitude. In C. Murchison (Ed.), A history of psychology in autobiography, Vol. 3 (pp. 181-213). Worcester, MA: Clark University Press.

Moran, R. (1981). Knowing right from wrong: The insanity defense of Daniel McNaughten. New York:Free Press.

Münsterberg, H. (1908). On the witness stand. Garden City, NY: Doubleday.

Otto, R. K., \& Heilbrun, K. (2002). The practice of forensic psychology: A look toward the future in light of the past. American Psychologist, 57, 5-18.

Saugstad, P. (2018). A history of modern psychology. Cambride, United Kingdom: Cambridge University Press.

Sommer, A. (2012). Policing epistemic deviance: Albert von Schrenck-Notzing and Albert Moll. Med. Hist., 56(2), 255-76.

Stern, L. W. (1939). The psychology of testimony. Journal of Abnormal and Social Psychology, 34(1), 3-20. https://doi.org/10.1037/h0054144

Tymn, M. (2011). Biography of Baron Albert von Schrenck-Notzing (1862-1929). Academy for Spiritual and Consciousness Studies, Inc.. Retrieved 7 September 2014, from http://www.ascsi.org/ASCS/Library/LegacyRoom/Biographies/Schrenck_A.pdf

Wells, G. L., Memon, A., \& Penrod, S. D. (2006). Eyewitness evidence: Improving its probative value. Psychological Science in the Public Interest, 7(2), 45-75. 